\title{
Our Short Talks
}

\author{
Pierandrea lo Nostro \\ Department of Chemistry "Ugo Schiff”, University of Florence, Italy \\ E-mail: pierandrea.lonostro@unifi.it
}

We recently organized the first edition of Substantia Short Talks to discuss some hot topics within the community of our journal. It was a recorded online event, that took place online on July 1, 2021, at 4 pm CEST.

In 2020, during the Covid-19 pandemic that forced us to restrain or limit our social and cultural activities, we thought to offer a lively cultural happening to strengthen our interactions and to ponder on some remarkable issues that affect our lives as scientists and citizens in a globalized world.

Examples that came up to our minds were quite some. Just to mention a few: the protection of intellectual property and the worldwide distribution of life-saving drugs (e.g. the anti-Covid vaccines) at very low costs; the relationship between science and politics, i.e. Black Lives Matter and the harsh debate between some international scientific journals and publishers; or the denial of freedom and democracy and even the lack of scientific dissemination in some countries, and so forth.

Not to speak about the side effects of the frenzied race to publish and the slavery to bibliometric indicators. What are the most important forces that drive research and dissemination in science today?

And what can we do to improve the state of the communication between the society and scientists? What does the pandemic have to say in this respect?

These are only a few among the several questions that spring from our minds.

And their echo often reverberate in Substantia as key points of some articles.

These are the reasons why we decided to organize these "short talks" as a parallel contribution to our efforts to make science more transparent.

This time our event features three contributions on peer review, big science and on the most advanced outcomes of current studies carried out by a young researcher in a specific field of Chemistry.

Each contribution lasted 20 minutes, leaving room for questions and answers.

We began with Seth Rasmussen from North Dakota State University in Fargo, who spoke about "The good and the bad of peer review".

Peer review started in 1831 in the UK with Willian Whewell who proposed to receive the comments of two fellows of the Royal Society on submissions to the Philosophical Transactions.

Peer review truly is the central core of scientific publishing. It is necessary to guarantee the reliability of a paper, in the scientific community but also before the society.

This process is the real core for the publication, of a reliable, solid and trustable article.

Interestingly, not so many people know that there are different kinds of peer review: single blind, double blind, post-publication, open, transparent, and collaborative peer review. ${ }^{1}$

Sometimes the process is rough, for different reasons, and the editorial staff has to handle this crucial and delicate step very carefully. In any case this is by far the most important stage in the publication process.

Then it was the turn of Helge Kragh, from the Niels Bohr Institutet in Copenhagen. He gave an historical overview on "Big Science: Opportunities and Challenges". This is a key issue with strong political ramifications. In fact big projects are so expensive that only governmental agencies can provide the necessary financial sources. They may also include other non scientific roles, such as managers, technicians, officers, secretaries, public accountants, and so forth. The work is usually carried out in a centralized system of large scale facilities 
where big and sophisticated, very expensive machines are employed, for example particle accelerators (CERN in Europe) or neutron sources (ORNL in the US).

The term "big science" was introduced by Derek J. De Solla Price, in a 1963 book that presented an overview of the 1962 Brookhaven National Laboratory Pegram Lectures. ${ }^{2}$

Certainly the topics and questions addressed in big projects are of paramount importance for science and for the society, however some significant drawbacks exist. For example the incredibly huge number of co-authors, ${ }^{3,4}$ sometimes larger than 5,000 ! This fact has important negative consequences, for example the impossibility to establish each author's credits (who did what), practical problems (e.g. answering the reviewers), and ethical issues. Of course when such a gigantic amount of money is invested, labs and instruments must work full time, with the consequence that methodologies and techniques may take the advantage over topics and science.

The third contribution was from Andreas Lesch, a young electrochemist working at the University of Bologna. His presentation "Electrochemical detection of viable bacteria and biofilms" addressed some hot topics, particularly in view of the next pandemic that some expect will be due to antibiotics resistance in pathogens, ${ }^{5}$ and of controlling the growth of biofilms on all kinds of surfaces.

Electrochemistry concepts and techniques can be very useful in the detection of viable bacteria, particularly when time is a key issue for establishing the correct therapy. The main conclusions of the presentation were the production of flexible and reproducible electrodes through inkjet printing, ${ }^{6}$ their application to detect viable bacteria, ${ }^{7}$ and the opportunities given by scanning electrochemical microscopies for investigating biofilms. ${ }^{8}$

In line with Substantia's vision and scopes this talk on the most recent advances in research in this particular field, was combined with the two previous contributions that do deal with current science activities but in another way.

This attitude of the journal springs from our interand multidisciplinary interests.

Today science is deeply divided, there are only few chances to exchange high level information between scientists working in different fields. In other words, the unification of knowledge is a fantasy, due to the over-specialization and to the reluctance to make contents and concepts easily available to other scientists. It is not a question of science popularization, it is a question of sharing. And of promoting truly interdisciplinary studies.

\section{NOTES}

1. https://authorservices.wiley.com/Reviewers/journalreviewers/what-is-peer-review/types-of-peer-review. html

2. De Solla Price, D.J. Little Science, Big Science. 1963. New York: Columbia University Press.

3. Aad, G. et al. Combined Measurement of the Higgs Boson Mass in $p p$ Collisions at $=7$ and $8 \mathrm{TeV}$ with the ATLAS and CMS Experiments. Phys. Rev. Lett. 2015, 114, 191803.

4. CMS Collaboration., LHCb Collaboration. Observation of the rare $B_{s}^{0} \rightarrow \mu^{+} \mu^{-}$decay from the combined analysis of CMS and LHCb data. Nature 2015, 522, 68-72.

5. Nadimpalli, M.L.; Chan, C.W.; Doron, S. Antibiotic resistance: a call to action to prevent the next epidemic of inequality. Nat. Med. 2021, 27, 187-188.

6. Zhu, Y.; Jović, M.; Lesch, A.; Tissières Lovey, L.; Prudent, M.; Pick, H.; Girault, H.H. Immuno-affinity Amperometric Detection of Bacterial Infections. Angew. Chem. Int. Ed. 2018, 57, 14942-14946.

7. Nagar, B.; Jović, M.; Costa Bassetto, V.; Zhu, Y.; Pick, H.; Gómez-Romero, P.; Merkoçi, A.; Girault, H.H.; Lesch, A. Highly Loaded Mildly Edge-Oxidized Graphene Nanosheet Dispersions for Large-Scale Inkjet Printing of Electrochemical Sensors. ChemElectroChem 2020, 7, 460-468.

8. Darvishi, S.; Pick, H.; Oveisi, E.; Girault, H.H.; Lesch, A. Highly Loaded Mildly Edge-Oxidized Graphene Nanosheet Dispersions for Large-Scale Inkjet Printing of Electrochemical Sensors. Sensors \& Actuators: B. Chemical 2021, 334, 129669. 